convenient to turn the nutrient cylinder out of the test-tube into a Petri's dish by means of gentle heat. The colonies can then be examined with considerable ease. If further cultivation is desirable the Petri's dish can be put into the incubator. If, on the other hand, it is desired to preserve the nutrient cylinder a few drops of formol can be poured into the dish, and thus a formol chamber is produced. Formol has in my experience proved itself to be a valuable addition to the laboratory both as a disinfectant and as a hardening agent.

In conclusion, it is almost impossible to exaggerate the services that bacteriology has already rendered to clinical work. Owing to it diphtheria is now perbaps one of the best understood of diseases. Thus in diphtheria is illustrated the happy result of judiciously combined clinical investigation and laboratory research. I have to thank Dr. Barrs for permission to make use of the case referred to in this paper, and Dr. Roberts, the resident medical officer at the Infirmary, for some valuable notes.

Leeds.

\section{A CASE OF THORACIC ANEURYSM.}

BY JOHN C. UNDERWOOD, L.R.C.P.LOND., M.R.C.S.ENG.

As the following case appears to me to present some unusual points I renture to think it may interest some of the readers of THE LAXCET.

On May 13th, 1895, I was called to see a man aged fifty, and found him sitting up in bed suffering from considerable pain in the chest, and was given the following account of his illness. Until November, 1894, he had, with the exception of slight pain in the chest, enjoyed very good health; he had been physically very strong and had done a good deal of very hard work, including lifting heavy weights. About that time he experienced severe pain in the neighbourhood of the third costal cartilage of the left side, which obliged him to leave a van he was with and return home by train, when, and for some considerable time afterwards, he was attended by a medical man. His family history was good; his father died at the age of seventy-eight years ; his mother, aged seventy-six years, suffered from some "liver trouble"; all his grandparents had attained old age; and his brothers and sisters were enjoying good health. As regards the patient's personal history there had been a possible contraction of syphilis when he was quite young, and this was, I think, borne out by several miscarriages on the part of his wife, no child living for any length of time. He used at one time to take a considerable quantity of beer, but had never been a drunkard. On examination he was found to be pale, worn, and anxious-looking; the pupils of the eyes were equal and medium-sized, the conjunctivæ were pale, and there was no arcus senilis. The tongue was pale and moist and protruded in a direct line. The bowels were regular. He had a slight hacking cough, rather harsh, but not brassy. His appetite was fairly good. He never had a headache. The chest was very well formed and broad, the ribs were well arched, and no superficial veins were apparent. In the lungs there was healthy vesicular breathing, except opposite the vertebral border of the left scapula, where there were slight dulness and pain, and the breath sounds were weak over an area measuring an inch and a half by two inches and a half. The heart dulness was normal, the sounds being rather weak The pulse was medium, soft, compressible, and not persistent, and that of the left side rather the fuller; this latter condition continued to the end. Dulness, pulsation, and tenderness were present at the left edge of the sternum, on the level of the third costal cartilage, just above the heart dulness. The abdomen was normal. the liver, spleen, and kidneys being normal also. No albumin was present in the urine. In the neck there were a few slightly enlarged glands at the posterior edge of the sterno-mastoid muscle. In June he complained that he could feel a trickling in his left chest. this I thought to be due to the rupture of a vein behind the sternum from pressure of the aneurysm. At the end of the month he began to experience severe anginal attacks, the pain proceeding from the neighbourhood of the swelling and running thence down the left arm, the hand becoming quite cold to the touch and the pulse being considerably lessened in volume, its rate being 92 per minute. The swelling enlarged gradually and to the left side, the pulsation, of an expansile nature, becoming more marked; the pain also grew more severe at times. I now recognised that the true aneurysmal sac had given way and that a false aneurysm was forming in the left anterior mediastinum. Eventually the whole front of the left chest became dull and pulsating, and the heart was gradually pushed behind the sternum. Breath sounds could be beard feebly for a time over the front of the chest and, up to the last, over the back, though much less than normal. Those on the right side became somewhat exaggerated, but not to the extent of being puerile. In October the second and third ribs were becoming absorbed, and at the last no ribs could be felt in front as far down as about an inch or an inch and a half below the nipple. At this time the tumour projected forwards to the extent of an inch and a quarter above the level of the ribs and was pulsating in a general expansile manner. Just before each of the frequently recurring attacks of pain the patient always described his sensations as "lumpy" or " in knots." Ten days before his death the tumour reached from the first rib to the seventh, and laterally from the right side of the manubrium to the axilla, its measure. ments being ten and a half inches by fourteen and a half inches, and one and a half inches from before backwards, as nearly as I could judge. In the early part of November 1 noticed that the left arm and hand were swollen, and also the back of the right hand to a slighter extent, and the superficial veins over the front of the tumour were enlarged, especially near the manubrium, the skin was dusky, and the wall of the tumour was becoming much thinner. Later a pulsating swelling about half an inch in diameter formed at the level of the fourth left costal cartilage, one inch from the sternum. When this was on the point of bursting I incised it and removed some blood-clot. This I did because considered that the false aneurysm had perforated slightly at the higher point mentioned and was dissecting its way downwards between the skin and the sac. I applied antiseptic dressings to the opening, strapped them down firmly, and then applied a pad which was affixed to a stout piece of twill shaped and worn like an "ephod," this being kept tightly in position by four bandages, one from each corner. On Dec. 3rd, as he usually lay on his left side, but frequently changed his position, the "ephod" became displaced, and I was hurriedly summoned to stop a bæmor. rhage from the aforementioned small opening; this was easily accomplished, and he lost but a small quantity of blood, the nurse having been instructed to press on the skin between the outer opening and where the inner one was situated. On the 5th and 7th there were two more attacks of hæmorrhagè, and he lost considerably more blood and was much exhausted thereby. On the 11th, at 5 A.M., I was called, as another hæmorrhage had taken place. I found him unconscious, with widely dilated pupils, no pulse perceptible at the wrists, and the heart sounds scarcely audible. He partially recovered consciousness about 9 A.M., but on the following day he had no recollection of the previous one. On the 14th I was three miles distant when I was summoned to him again. On my arrival he was pulseless and unconscious. He was surrounded with hot-water bottles, sulphuric ether was injected subcutaneously three times, and one pint of normal saline fluid was passed into the rectum. He never rallied, and died in an hour. The treatment consisted of the exhibition of iodide of potassium up to 160 grains daily, morphia, belladonna, aconite, bromide of potassium, trinitrine, diaphoretics and diuretics, aperients, and subchloride of mercury in one-grain doses (but he only took six of these tabloids, as he became salivated), together with the application of belladonna plasters and inhalations of nitrite of amyl; he also was given subcutaneous injections of morphia and of morphia and cocaine, this latter combination relieving the pain more quickly. He had good nourishing food in as dry a form as possible, with plenty of fat, fluids being limited to one pint daily.

Necropsy.-Only the chest was allowed to be examined. Incisions were made through the skin along the clavicle, down the sternum, and across to the axillary line. The front wall of the false aneurysm was formed of skin and pectoral muscles only, these muscles being evenly spread all over the front of the tumour. At the inner part, near the sternum, there was a small opening through the fibres of the pectoral muscles. The whole of the left anterior mediastinum down to the diaphragm was filled with more than two quarts of recent blood-clot, the lung being squeezed to the back 
in a thin layer and matted at its inner edge to the pericardium. The whole front part of the second, third, fourth, and fitth ribs and part of the sixth rib and costal cartilages were absorbed, except a small piece of the third costal cartilage, which projected into the clot. There were some loose pieces of rib and cartilage in the substance of the clot. The pericardium contained about half-a-pint of yellowish-brown serum. The heart was collapsed and covered with a thin layer of fat, its cavities being dilated and absolutely empty, and its walls flabby and pallid. The tricuspid opening admitted the tips of three fingers, the mitral two fingers, their valves, together with those of the pulmonary artery, being normal. The aortic opening permitted the indexfinger to be passed freely through it; its valve was slightly incompetent. Immediately beyond the valve the true aneurysm commenced; it was quite globular, easily contained my closed fist, and lay behind the middle and upper bones of the sternum. The inner walls were extremely atheromatous, and between the openings of the innominate and the left carotid arteries there was a bony plate which snapped when I bent it. The aorta as far down as I could remove it presented much atheroma. The openings of the innominate, left carotid, and subclavian arteries were quite normal, as well as the arteries themselves. Antero-laterally to the left there was a ragged rent in the sac-wall large enough to admit the tips of my four fingers, opening directly into the false aneurysm. The front and right sides of the sac were lined by a nearly white laminated and organised layer of bloodclot about three-eighths of an inch thick. There was scarcely any fluid in the sac. I became aware, when too late, that I should have been allowed to remove the specimen.

Luton.

\section{Clinitall atos: \\ MEDICAL, SURGICAL, OBSTETRICAL, AND THERAPEUTICAL.}

\section{A CASE OF PUERPERAL HYPERPYREXIA.}

By H. Laird Pearson, M.R.C.S. ENG., L.R.C.P.LoNid.

THE patient, a married woman, was delivered on Oct. 12th, 1895, the head of the fotus being assisted over the perineum with forceps. On the evening of the fifth day the temperature was $107.4^{\circ} \mathrm{F}$, having been preceded by a sharp rigor. There was no abdominal distension or tenderness; the lochia had ceased. The uterus was at once washed out with a 1 in 5000 sublimate solution; a powder consisting of calomel, 4 gr., and acetanilid, 10 gr., was given. In thirty-five minutes the temperature had fallen fire degrees. The acetanilid was repeated every twelve hours, the uterus being washed out again twelve hours later. On the evening of the seventh day the temperature, which had remained at about $102^{\circ}$, rose to $106^{\circ}$. The uterus was again syringed out-making the third and last time-and in addition to the diurnal dose of acetanilid two grains of muriate of quinine were given every two hours. The temperature for the next fortnight gradually dropped to the normal. The acetanilid was given regularly for twelve days, the patient exhibiting fairly-marked continuous cyanosis; the quinine was administered a week longer. She is now well. The infant was still at the breast when the temperature stood at $1074^{\circ}$; it died twenty-four hours later after bilions vomiting and convulsions.

Remarks.-Seven weeks earlier I was in attendance on a case of puerperal septicrmia that ended fatally; one week earlier a lying-in case gave me much anxiety on account of fever lasting a week; two other confinements during the same period were attended by no unfavourable symptoms. I must admit that I saw little hope for the patient with her temperature at $107.4^{\circ}$ and obvious septic intoxication, and that the good result that followed was owing to the acetanilid. I bave used the drug very extensively and place much reliance upon keeping the patient fairly cyanosed under it. I have never seen it produce alarming symptoms.

Holt Hill, Tranmere, Eirke..he id.

\section{EXTENSIVE LUPUS OF THE FACE GREATLY IMPROVED IN APPEARANCE BY AN ARTIYICIAL NOSE AND MASK.}

BY E. J. SMYTH, M.B., B.S. Lond.,

RESIDENT MEDICAL OKFICER, CITY INFIRMARY, BIRMINGHAM,

THE patient is a man aged twenty-seven years who has been under the care of Dr. Sydney Short in the Infirmary, Birmingham, for some months. He has suffered from lupus

Fig. 1.

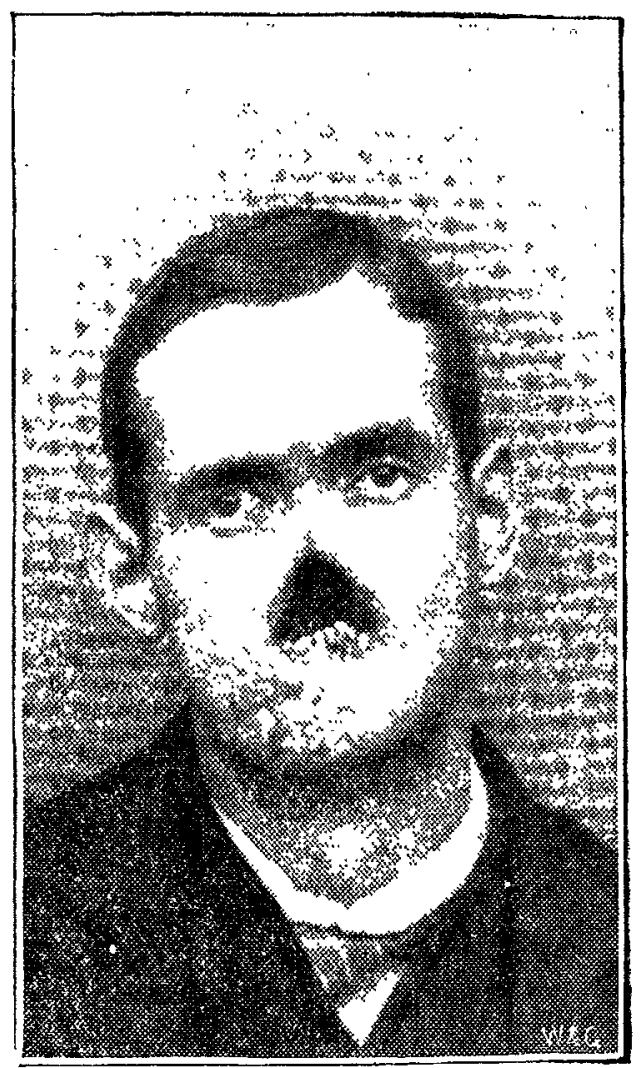

of the face since twelve years of age, and, as will be seen by the illustration (Fig. 1), the resulting destruction of parts is very extensive. The nose, the adjoining parts of the cheeks,

FIG. 2.

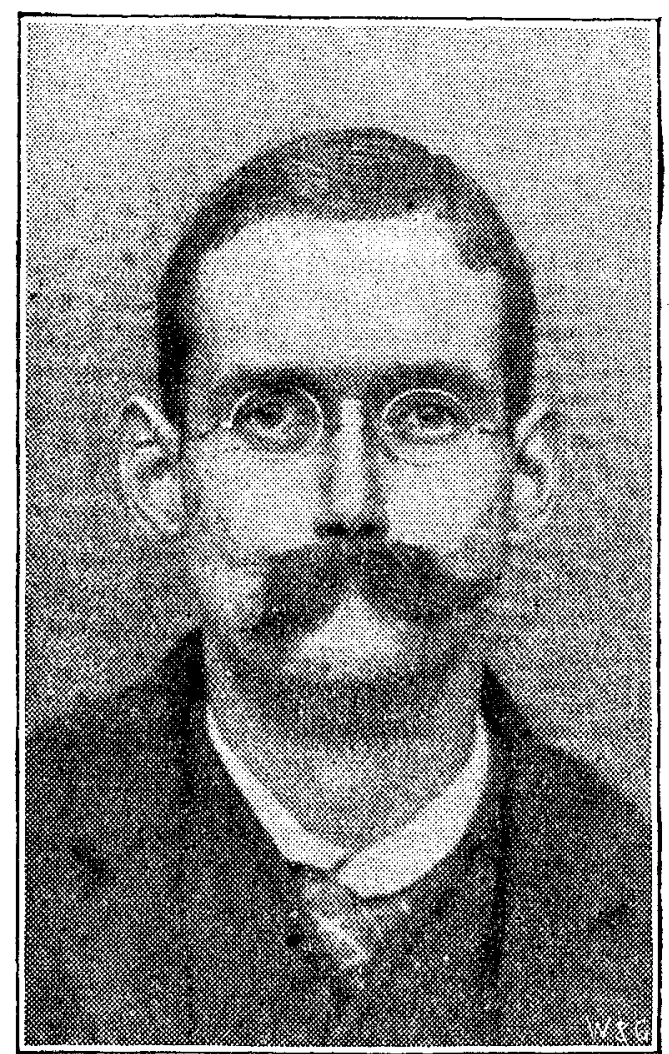

the hard and soft palate, the alveolar portions of the superior maxilk, together with the chief parts of the walls of the nasal fossæ, are completely destroyed. The mask, which 